\title{
A legitimidade presente no silêncio das palavras de Kaka Werá Jecupé
}

\author{
Bianca Basile Parracho ${ }^{1}$
}

\begin{abstract}
Resumo: Todas as vezes que dissemos adeus, do indígena txucarramãe Kaka Werá Jecupé, é o ponto de partida, neste artigo, para refletir sobre o percurso da autenticidade de obras como essa, de autores marginalizados, muitas vezes silenciados e deslegitimados pela academia. A universidade deveria ser um espaço capaz de integrar o conhecimento à realidade dos atores sociais, portanto, nessa direção, será discutido o papel da academia e dos intelectuais diante desses "outros tipos de conhecimentos e saberes" (MATO, 2004). A possibilidade de diálogo entre as "narrativas móveis" (WALTY, 2005) e o cânone literário nos mostra que uma está intrinsecamente ligada à outra, e que essa troca cultural é essencial. Nesse sentido, este trabalho traz à tona um dos pensamentos de Michel Foucault, quando ele afirma que a educação é capaz de manter ou de modificar o poder da apropriação dos discursos. A trajetória de Kaka Werá Jecupé relata esse entrecruzamento de culturas, representando uma busca de si e do outro. Na autobiografia do autor está presente, além da sua trajetória, uma forte crítica à mídia que muitas vezes transforma a cultura indígena em representações exóticas com fins sensacionalistas, como está claro no livro de Kaka Werá Jecupé. Um Brasil desconhecido por muitos brasileiros é relatado através da experiência do indígena txucarramãe e essa necessidade de falar para mais pessoas fez com que Kaka Werá investisse na escrita do português (e do inglês, já que a edição de Todas as vezes que dissemos adeus é bilíngue) para que pudesse mostrar seu povo. Para analisar esse ponto, remetemos ao que Pierre Bourdieu nomeou de "autorização" para falar, no que refere às condições sociais de produção e reprodução do discurso. O objetivo principal deste trabalho é levantar a discussão acerca do silenciamento de expressões literárias como Todas as vezes que dissemos adeus.
\end{abstract}

Palavras-chave: Kaka Werá Jecupé; trocas simbólicas; legitimidade; academia.

\begin{abstract}
Whenever we said goodbye, by the indigenous txucarramãe Werá Jecupé Kaka, is the starting point in this paper to reflect on the authenticity's path of works from marginalized authors, like him, often silenced and delegitimized by the academy. The university should be a space able to integrate knowledge with the reality of social actors, so in that direction, this paper will discuss academy's role and also intellectuals' role in face of these "other types of knowledge and learning" (MATO, 2004). The possibility of dialogue between "mobile narratives" (WALTY, 2005) and literary canon shows us that one is intrinsically linked to each other, and that this cultural exchange is essential. In this sense, this work brings up thoughts of Michel Foucault, when he says that education is capable of maintaining or modifying the appropriation of discourses of power. The trajectory of Kaka Werá reveals this intersection of cultures representing a search for self and other. The

${ }^{1}$ Mestranda em Literaturas de Língua Portuguesa e Luso-Africanas pela Universidade Federal do Rio Grande do Sul. E-mail: bianca.basile@gmail.com.
\end{abstract}


autobiography of the author is present, in addition to his career, a strong criticism of the media that often transforms indigenous culture in exotic representations with sensationalist purposes, as is clear in the book of Kaka Werá Jecupé. An unknown to many Brazilians Brazil is reported through the experience of indigenous Txucarramãe and this need to talk to more people caused Kaka Werá invest in written Portuguese (and English, since editing Whenever we said goodbye is bilingual ) so he could show his people. To analyze this point, I refer to what Pierre Bourdieu coined the term "authorization" to speak, in regards to the social conditions of production and reproduction of speech. The main objective of this work is to raise the discussion of literary expressions as silencing Whenever we said goodbye.

Keywords: Kaka Werá Jecupé; symbolic exchanges; legitimacy.

Por isso eu passo a ser também a voz que partilha um aprendizado. Para nos superarmos, para sobrevivermos, para reinventarmos a vida.

Kaka Werá Jecupé

Este artigo aborda questionamentos surgidos a partir da leitura de Todas as vezes que dissemos adeus (2002), de Kaka Werá Jecupé. A história, em primeira pessoa, pode ser lida como uma autobiografia do txucarramãe ${ }^{2}$, proporcionando uma série de reflexões acerca da escrita em português pelo indígena.

O passo inicial desta reflexão é a dificuldade de reconhecimento dessa literatura e de outros tipos de saberes e conhecimentos pela academia, passando pelas questões que envolvem o poder do discurso e a autorização para falar. Nesse sentido, e entendendo a necessidade de provocar o diálogo entre a cultura popular/oral e o cânone, chegaremos ao princípio da trajetória de Kaka Werá, quando entendemos que sua intenção é “...conversarmos juntos ao pé do fogo, para descobrirmos os brasis" (2002, p.17). A partir daí, desde rituais sagrados até o contato com a "civilização", passando por inúmeros diálogos culturais e simbólicos, Kaka Werá apresenta uma releitura da colonização e uma possibilidade de outro olhar sob o passado.

\footnotetext{
${ }^{2}$ Txucarramãe significa "guerreiros sem arma".
} 
Sem se aproximar do pessimismo - pelo contrário, carregando esperança em busca de si e do outro -, o txucarramãe mostra que é possível um intercâmbio cultural rico sem perder sua essência. Para tanto, a aprendizagem da escrita pelos indígenas, na visão de Kaka Werá, é fundamental. Ao mesmo tempo em que representa um instrumento de dominação, a escrita também é uma forma de resistência nas mãos dos povos originários.

No caso de Jecupé, a escrita oferece ainda a possibilidade de ensinar aos "civilizados" o que ele chama de conhecimentos ancestrais do seu povo - conhecimentos esses que permitirão, como nos explica, a salvação do planeta da destruição causada pelo consumismo da sociedade moderna. (SÁ, 2006, p. 258)

Por fim, será abordada a questão da presença e da importância da escola nas aldeias indígenas, com base em pesquisas e estudos que têm sido realizados nesse âmbito, assim como a complexidade que envolve essa discussão.

\section{Diante da marginalização: a academia, o poder simbólico e a (des)legitimação}

Para Daniel Mato (2004), os discursos modernizadores da ciência, em especial no espaço latino-americano, vêm ganhando força nas últimas décadas. O cerne desse direcionamento está, para o autor, em procedimentos adotados pelos governos e universidades, que adotam medidas extremamente quantitativas (o que acaba por aproximar as Humanidades e Ciências Sociais das chamadas "Ciências Exatas") para promover apoio financeiro a tais pesquisas. Esses discursos modernizadores podem ser entendidos como os responsáveis por transformar pesquisas em algo denominado "científico", de caráter extremamente objetivista e academicista. Esses estímulos, longe de fortalecerem um pensamento crítico que se aproxime da realidade e dos próprios atores sociais, tendem a aumentar ainda mais a distância que os chamados intelectuais mantêm da sociedade. 
Para Mato, a reflexão deve partir do questionamento da hegemonia instaurada nas universidades que, quando deveriam justamente servir à comunidade, acabam por cimentar ainda mais os muros que separam esses "dois mundos". Esse isolamento em que permanecem os pesquisadores científicos (que Daniel Mato também chama de "autocontemplação") contribui para a deslegitimação de outros saberes, deixando-os à margem de qualquer valorização acadêmica e sendo até indesejados dentro da grande maioria das universidades. Na medida em que deveria voltar seus esforços à sociedade que vive em seu entorno, o que acontece é o extremo oposto: o trabalho intelectual passa a se desvincular da reflexão política, excluindo qualquer possibilidade de diálogo e troca entre saberes que circulam do outro lado da fronteira.

Nesse sentido, continuamos a discussão considerando as contribuições de Ruth Finnegan (2006) no que diz respeito à diferença que se inscreve entre literatura escrita e literatura oral. Sabemos que a cultura e a herança indígenas provêm da oralidade, e que Kaka Werá precisou de um longo caminho para alcançar o domínio da escrita em língua portuguesa e o fez para que pudesse transmitir aos não indígenas a sabedoria de seu povo: escreveu para ser ouvido. Ainda que o tenha feito, é clara a resistência a essa literatura nas universidades. Para Finnegan, a questão é a grande distância que se coloca entre a presença e a ausência da escrita. Se uma obra escrita em português por um autor indígena já passa por diversos níveis de preconceitos, a literatura em forma oral é ainda mais deslegitimada e desautorizada, não só na academia como também na sociedade. Para a autora, é preciso que as duas formas literárias sejam pelo menos consideradas análogas.

São claras as diferenças entre a forma escrita de fazer literatura e a oralidade como forma literária. Uma delas, para Finnegan, é a variabilidade inevitavelmente presente na oralidade. De qualquer forma, essa diferença não é, de modo algum, negativa. Pelo contrário, marca a complexidade como 
característica fundamental da literatura oral. Diferenças como essa, para a autora, deveriam engrandecer a relação entre o oral e o escrito, e não servir como mais um marco para fortalecer a distância e a divisão que já existe entre essas duas formas de literatura.

Os povos originários tiveram sempre sua história contada por um outro, fato que colaborou para a construção de preconceitos que são nítidos até hoje. Com a visão de apenas um lado da história - e, nesse caso, o lado de quem conta quase sempre é o lado do dominador - a sociedade se fixa em cima de relatos exteriores à comunidade em questão. Para Regina Dalcastagnè (2008), esse silêncio dos grupos socialmente marginalizados só é quebrado quando há uma produção literária de um integrante do próprio grupo. Ainda assim, a legitimidade e a autenticidade da obra são colocadas em jogo, em função de um elitismo característico do campo literário. Isso se dá pelo fato de que, historicamente, as classes populares têm acesso muito mais restrito a ambientes como a universidade, por exemplo. Foucault (2006) já atentava para a questão da apropriação da voz, quando afirmou que controlar o discurso é o mesmo que negar o direito que determinado grupo tem de falar. Uma das formas de controle, ainda para Foucault, é o sistema de educação, que se dá como uma maneira política de manter a apropriação dos discursos, junto com os poderes e os saberes que eles trazem. Para Dalcastagnè, é preciso democratizar também a literatura, colocar ao lado dos cânones o que ainda continua sendo considerado exótico, apenas por não ser conhecido.

Nesse sentido, é visível a ausência quase total de representantes das classes populares na literatura contemporânea brasileira. E Dalcastagnè não se refere apenas à questão da autoria, mas considera também essa ausência no âmbito dos personagens. “(...) é possível descrever nossa literatura como sendo a classe média olhando para a classe média” (2008, p. 79). A autora não menospreza de forma alguma a literatura que surge daí, mas atenta para a 
limitação de perspectiva resultante dessa uniformização. Da mesma forma que as classes populares têm acesso mínimo à fala e ao poder, também isso se reflete na literatura, apontando um forte grau de subalternidade promovido e alimentado pelos detentores do poder do discurso.

Ainda sobre o processo da exclusão, Walty (2005) considera que esse fenômeno também é consequência da passagem da economia industrial para a pós-industrial, que dispensa o trabalho e o trabalhador, alimentando-se do próprio capital e do mercado. Para a autora, o crescimento da exclusão de grupos sociais pode estar anunciando a diminuição da pluralidade interativa. Isso se dá porque mais pessoas morando na rua, mais crianças sendo exploradas, cada vez mais desempregados sem perspectiva não são representações de pluralidade cultural, mas sim definições de uma ordem social excludente, que separada justamente porque uniformiza.

A discussão que aos poucos aparece em algumas universidades destaca a importância de refletir sobre conceitos como diferença e alteridade. De acordo com Walty, entretanto, mesmo concordando com essa quebra de fronteiras entre o global e o local, existe o risco de se perderem as especificidades daquilo que é dado como abordagem literária. Se nos colocamos no lugar do outro a diferença pode desaparecer, impossibilitando qualquer diálogo verdadeiro. Esse diálogo, para a autora, seria concretizado colocando em contato as narrativas móveis (mitos, lendas) em espaços marginais, contadas por narradores também marginais (índios, negros). Já que o cânone literário retoma, em grande parte, histórias e saberes orais, e a produção cultural popular também absorve elementos da chamada cultura erudita, é contraditório perceber que essas duas direções sejam consideradas tão opostas.

Para concretizar essa direção de pensamento, Walty relata a experiência de uma associação (Asmare) formada por ex-moradores de rua em Belo Horizonte. 
Esse contexto da reciclagem, do reaproveitamento, da inserção de resíduos novamente no sistema, amplia o espaço do catador de materiais recicláveis; e é por meio do reaproveitamento daquilo que é descartável que se dá o "reaproveitamento" das pessoas. (WALTY, 2005, p. 57).

Se antes a cidade enxergava essas pessoas como parte do lixo, agora, a partir dessa organização, a reciclagem se transformou em um trabalho que passa a obrigar a sociedade a olhar não só para os ex-moradores de rua, mas principalmente para o sistema a sua volta. Mais do que ocupar suas vidas, esses trabalhadores conseguiram inserção no sistema, de forma legitimada, como exige essa sociedade que vive uma "globalização seletiva", em que grande parte da população não tem direito à cidadania por se não se enquadrar nos moldes atuais de consumo. Com renda obtida a partir desse processo de reciclagem e transformação do lixo, os associados podem ter uma vida digna.

Com a ajuda de artistas plásticos, embalagens de ovos de páscoa viram sutiãs criativos, garrafas de plástico viram adereços de cabeça os mais variados, peixes e outros animais são feitos com papelão e recobertos com papel colorido ou tinta, CDs e fitas velhas viram enfeites de vestidos mirabolantes e assim por diante. (WALTY, 2005, p. 60)

Uma das atividades do grupo, voltada para um carnaval feito somente de reciclagem de resíduos, tem um objetivo que vai além da questão visual: "Fazemos o carnaval para que os outros prestem atenção em nós", afirma a líder da associação. Mais do que conquistar cidadania, eles querem fazer parte do sistema, ainda que para isso precisem utilizar os mesmos recursos já instaurados na sociedade, como a celebração do carnaval.

Walty recorre ao conceito de bricolage, cunhado por Lévi-Strauss, para entender que essa união de ex-moradores de rua, com a finalidade de transformar resíduos diversos dando-lhes uma nova forma, imprimindo seus próprios traços na criação, resulta na formação de uma identidade para esse 
grupo. Para a pesquisadora, "essa forma de criação é libertadora". O ponto central desse exemplo está em compreender que a linguagem carnavalesca produzida por esses trabalhadores necessita de fato ser "lida/ouvida por diferentes leitores, que, antes de tudo, a considerem como um texto" (WALTY, 2005, p. 64).

Nessa mesma linha de raciocínio, Bourdieu (1996) reitera que falar, simplesmente, não é o foco do questionamento. É preciso pensar a respeito da autorização necessária para falar. O sociólogo francês afirma que o uso da linguagem depende da posição social em que se encontra o locutor, além do seu acesso aos instrumentos legítimos de expressão. Uma vez que a linguagem representa, histórica e culturalmente, uma forma de autoridade, o porta-voz precisa estar munido dessa autorização que lhe dá poder para falar e ser ouvido. Caso essas condições não sejam estabelecidas, não haverá reconhecimento e de nada adiantará a fala, sendo essa a forma que o poder simbólico se estabelece até hoje. Para Bourdieu, entretanto,

\begin{abstract}
a autoridade da língua legítima reside nas condições sociais de produção e de reprodução da distribuição entre as classes do conhecimento e do reconhecimento da língua legítima e não no conjunto das variações prosódicas e articulatórias definidoras da pronúncia refinada como sugere o racismo classista, e muito menos na complexidade da sintaxe ou na riqueza do vocabulário, quer dizer, nas propriedades intrínsecas do próprio discurso. (1996, p. 91-93).
\end{abstract}

\title{
A escola e a escrita dentro das comunidades indígenas
}

Há séculos representada por vozes alheias, a cultura indígena é vista pela maior parte da sociedade como algo distante, menor, periférico. Essa visão, sabemos, tem certo respaldo histórico. $\mathrm{Na}$ época da invasão do Brasil pelos portugueses, e a consequente necessidade vista pelos colonizadores de catequizar o povo indígena pelo trabalho jesuítico, transformaria para sempre a trajetória da cultura indígena. 
Todas as vezes que dissemos adeus, livro de Kaka Werá Jecupé, publicado em 2002, é um exemplo concreto das intempéries desse caminho, já que não são muitas as obras escritas por indígenas brasileiros refletindo acerca da colonização. D’Angelis (2007) levanta essa questão quando reflete sobre os povos indígenas não terem se apropriado imediatamente da escrita do colonizador, já que a missão jesuítica teve forte influência na cultura indígena.

Em algumas sociedades originárias, instrumentos de metal e até armas de fogo foram rapidamente assimiladas. A escrita, porém, teve percurso distinto. Ainda de acordo com a reflexão de D’Angelis, é evidente que o fato dos jesuítas portugueses terem sido minoria, fez com que eles próprios tivessem que aprender a língua local, para que a catequização pudesse se efetivar. Entretanto, com o tempo, a proximidade com os não indígenas e a presença da escola nos arredores das aldeias (século XX) trouxe essa questão à tona.

Com a preocupação de manter a cultura ancestral viva para as próximas gerações e de registrar a própria história, lideranças indígenas passaram a buscar possibilidades de tornar o ensino nas aldeias realmente efetivo e útil. Além do fortalecimento da própria língua, algumas tribos também precisaram buscar na língua do colonizador uma forma de troca, comunicação e interação entre suas culturas. Para D'Angelis, a introdução de um programa bilíngue é essencial.

Ainda assim, o autor levanta questionamentos para que se reflita sobre a autonomia que terá uma literatura indígena em que seus praticantes adotam modelos da língua do colonizador/dominante. De qualquer forma, é certo que hoje o contato das comunidades indígenas com a sociedade dos não indígenas significa, em grande medida, uma proximidade da oralidade indígena com a escrita não indígena.

Para D'Angelis, é preciso observar que a escola introduzida em algumas aldeias, principalmente na primeira metade do século XX, representava locais em que os indígenas eram expostos à língua portuguesa. Sem dúvida, durante 
décadas, essa ação serviu de combate à própria cultura indígena, uma vez que o ensino se dava de forma monolíngue.

Nos anos de 1990, surgiu a preocupação em inserir na escola da aldeia o ensino da língua indígena, para que a comunidade e sua história se tornassem de fato um referencial, principalmente para o mais jovens; uma forma de manter viva a cultura indígena, na sua própria língua. Entretanto, quase não há investimento em produção de livros em língua indígena, a fim de se efetivar de forma concreta esse ensino. Não basta simplesmente transpor histórias orais para a forma escrita. De todo modo, se a forma oral já não transmite como antes a história do povo, a escrita pode ser uma forma de resguardar a memória ancestral para as gerações futuras.

Retomando a escrita de Kaka Werá Jecupé, sua obra, em português, é de extrema importância para a reflexão sobre o discurso e a legitimidade de um povo ainda marginalizado. Muito mais do que transmitir conhecimento das suas origens, o autor provoca o pensamento crítico sobre a colonização (inclusive atual) e mostra a possibilidade de olhar para a História de forma plurilateral. Sem rejeitar outras culturas, ao contrário, respeitando-as, Kaka Werá consegue mostrar que o aprendizado da língua portuguesa foi, no caso dele, uma forma de instrumento de resistência, de registrar a voz da insatisfação na língua do próprio colonizador, para que este possa também olhar a trajetória indígena por outro lado.

As autoras Menezes e Bergamaschi (2009), a partir de pesquisas em aldeias guarani, sobre a presença da escola nas comunidades indígenas, relatam que eles "referem-se a esses conhecimentos escolares como uma porta necessária que abre caminhos para circular no mundo não indígena, o mundo dos brancos" (2009, p. 130). De acordo com as pesquisadoras, as aldeias guarani entendem que precisam decifrar os caminhos da escrita e que preferem dominála, uma vez que podem colocá-la em seu favor. 
Maria Inês de Almeida (2009) coloca em discussão o lado contraditório que é possível perceber ao pensar/analisar a presença da escola na aldeia:

Por ser a casa da escritura, a escola instaura na vida indígena a contradição, o desvio, o deslocamento, e acaba por desfazer redes do já feito e do já sabido. A escola indígena trabalha na revitalização das tradições, mas, pela via da tradução, colocando em crise a própria memória. $(2009$, p. 75$)$

Como exemplo, Almeida cita uma escola indígena Krenak, em Minas Gerais, em que os professores desenvolvem um projeto baseado na história e na língua Krenak. A realização desse trabalho, porém, só se dá porque duas professoras de língua e cultura Krenak estão presentes em sala de aula. Do contrário, não haveria a presença da língua indígena. Como não existiu uma língua Krenak plenamente constituída, o ensino se dá pelo conhecimento das suas professoras, ou seja, se dá pelo texto, por uma espécie de tradução feita por todos os envolvidos: uma história que se imagina ter sido de determinada forma.

\section{Das vezes em que Kaka Werá disse adeus}

Já no prólogo de Todas as vezes que dissemos adeus, Kaka Werá relata que foi por meio de um sonho a certeza que teve sobre a missão de escrever contando sua história, que, como ele diz, história que viveu entre dois mundos (na sua comunidade indígena e na "civilização").

Neste sonho firmei o compromisso de traduzir da vermelha 'escrita-pintura' de meu corpo para o branco corpo desta 'pintura-escrita'. Cumprindo a tarefa nesse relato, para tingir o que até então no mundo tem parecido 'intingível', a mistura do vermelho sobre o branco resultando na cor da vida. $(2002$, p. 16)

Sentindo a necessidade de partilhar o conhecimento da tribo em que viveu, Kaka convida o leitor a descobrir, junto com ele, os brasis e os brasileiros: "Eu vim para nos despirmos" (2002, p. 17). Ao mesmo tempo, a 
ironia, muitas vezes por meio de intertextualidades, se faz presente de forma contundente no texto de Kaka: "Foi assim que comi o pão que a civilização amassou" (2002, p. 16). Em determinados momentos, é nítida a presença de uma consciência absoluta do passado colonial e do também presente neocolonialismo, o que ficará claro mais adiante.

Na década de 1960, os pais de Kaka, de origem txucarramãe, viviam no norte do país, de onde foram expulsos, tendo a aldeia sido atacada por "homens empunhados de pequenos trovões de aço" (2002, p. 22). Os poucos sobreviventes (alguns parentes de Kaka) foram morar perto de uma aldeia guarani, nas margens da represa Billings, zona sul da cidade de São Paulo. Foi assim que Kaka, ainda pequeno, incorporou-se aos guarani. Ao perder um amigo de infância, Kaka conta que foi iniciado, dessa forma, na lição de dizer adeus. Ao longo da sua trajetória, o autor nos contará outros momentos em que teve de dizer adeus.

Mais tarde, o pai de Kaka foi convencido por uma professora não indígena que seu filho deveria frequentar a escola. De nome Professor Manuel de Borba Gato, a escola também nos remete ao bandeirante paulista de mesmo nome que viveu na segunda metade do século XVII, participando da caça aos minérios no sertão brasileiro, da busca por indígenas para escravização e do extermínio de quilombos. O pai, ao ser questionado por Kaka o porquê de ir à escola, disse que essa era uma forma de defesa.

Me respondeu que era um lugar onde se riscava com traços o que se falava, e que qualquer um podia dizer exatamente o que se havia falado olhando para aqueles traços, mesmo que se passassem sóis e luas. Isso me deixou fortemente encantado. (2002, p. 31)

Assim, a escrita e a leitura ganharam vida na trajetória de Kaka Werá, e esse seria o início de uma longa caminhada em busca de si e do outro. 
A certidão de nascimento, o uniforme escolar, a foto na carteira de identidade e outros rituais que a "civilização" exigiu o cumprimento por parte de Kaka, o fizeram conhecer, aos poucos, como a aldeia e o seu povo estavam próximos demais da cidade, e cada vez mais longe de si mesmos. Essa imagem fica clara no momento em que Kaka relata a partida da mãe:

\begin{abstract}
Mas a mãe não resistiu aos novos costumes, ou às velhas saudades, não sei, talvez não tenha resistido à paisagem da vida desmoronando diante dos olhos. Talvez ela mesma não tivesse necessidade de resistir a qualquer coisa. $\mathrm{O}$ fato é que ela escolhera morrer cautelosamente, procurando não deixar qualquer marca na lembrança. Foi um dia perdido na infância, em que suas ervas não conseguiram curar minhas lágrimas. (2002, p. 33)
\end{abstract}

Alguns anos depois, a represa perto da aldeia já estava extremamente contaminada pela poluição vinda da cidade, e em seguida a tribo foi expulsa. Por uma trilha, chegaram à Aldeia de Peruíbe e Kaka conviveu com muitos guarani já sem esperanças: "Viviam desistidos de si. Sem música interior. Obstruídos pelas ruínas da terra sem males na memória" (2002, p. 36). Adiante, voltaram à proximidade dos guarani de São Paulo, na aldeia Morro da Saudade. A força espiritual de Gwirá-Pepó, cacique dessa tribo, e todo o ar que envolvia aquela comunidade trazia mais esperança para Kaka. Uma barragem dividia a vila da cidade, e essa proximidade levou o txucarramãe e se embrenhar nas cores acinzentadas da civilização.

Lúcia Sá (2006) expõe a ironia com que Kaka promove uma intertextualidade com a Carta de Pero Vaz de Caminha:

Com o tempo, passei a andar pelas largas trilhas da cidade chamadas avenidas. Percorri suas florestas de aço e comi de seus frutos artificiais para descobrir os brasis. Nos asfaltos por onde andei, se plantando, nada dá. Provei do bom e provei do ruim. Conheci uma qualidade de caciques que põem gravatas como na minha época de estudante e que, como dizia um antiquíssimo e histórico escrivão, andam deveras desavergonhados. (2002, p. 37) 
Para a autora, o humor dessa referência está na inversão que Kaka Werá provoca entre os papéis do narrador e do sujeito narrado. Ao colocar no lugar do narrador original (Pero Vaz de Caminha, que se refere ao povo colonizado) um indígena fazendo o mesmo, Kaka transgride a ordem colonizadora, questionando a falta de vergonha não na ausência de roupa dos indígenas, como o fez Pero Vaz, mas nas atitudes desavergonhadas dos engravatados da cidade.

Ainda levando em conta as reflexões de Lúcia Sá, essa postura na escrita de Kaka resulta em uma forma de crítica ao colonialismo utilizando uma ferramenta própria dos colonizadores no século XVI, a Carta de Caminha. Assim, o autor mostra como o processo de colonização não teve fim nos séculos passados, ao contrário, persiste até hoje. Mais do que isso, Kaka, ao escrever, solta sua voz e no decorrer de sua trajetória, é possível vislumbrar sua busca no outro e pelo outro, a busca da própria essência ancestral de sua história. Para entender-se dentro da "civilização", o txucarramãe bebe em fontes também ancestrais, também válidas e que também buscam o mesmo encontro.

Ao longo da trajetória narrada por ele mesmo no livro, Kaka percorre diversos lugares do Brasil, onde conhece pessoas de diferentes crenças e esses encontros resultam em uma grande celebração pelo perdão: Anhangabaú-opá (a dança do perdão). Até esse desenlace, porém, Kaka precisa também enfrentar as dificuldades de quem é visto pelo olhar do preconceito, da exploração e da indiferença. Essa dificuldade não aparece somente no livro em que Kaka conta sua história. Como autor, seu percurso é também delicado, já que uma obra de autoria indígena não faz parte e nem se aproxima da literatura canônica. Muitas vezes, por esse motivo, professores deixam de lado obras recentes de autores ainda não reconhecidos simplesmente por não terem alcançado a chamada autorização para falar/escrever.

Recorrendo novamente a Bourdieu, podemos considerar o professor como alguém munido dessa autorização, um porta-voz da autoridade de uma 
instituição que decide qual voz será ouvida. Foucault vai ao encontro desse pensamento quando afirma que "todo sistema de educação é uma maneira política de manter ou de modificar a apropriação dos discursos, com os saberes e os poderes que eles trazem consigo" (FOUCAULT, 2006, p. 44). Bourdieu ainda completa que a questão crucial da autoridade não está nas propriedades intrínsecas do discurso, mas sim "nas condições sociais de produção e de reprodução da distribuição entre as classes do conhecimento e reconhecimento" do que é legítimo (BOURDIEU, 1996, p. 91). Assim, é possível entender que o "silêncio das palavras" de Kaka aparece como uma dificuldade de ser ouvido, de receber essa autorização que representa unicamente um poder simbólico de onde se fala.

É possível perceber na prosa poética de Kaka Werá uma vontade ancestral de recontar sua história, de falar de seu povo e de se aproximar do outro, em uma tentativa sincera de se reaproximar de si mesmo. Kaka alcança esse encontro e mostra legitimidade no seu discurso, uma vez que transpõe as barreiras impostas pelo discurso do poder, apropriando-se de fatos concretos da história da colonização dos indígenas pelos portugueses e recontando passagens históricas de forma a produzir reflexão e dar eco à sua voz.

\section{REFERÊNCIAS}

ALMEIDA, Maria Inês de. Desocidentada: experiência literária em terra indígena. Belo Horizonte: UFMG, 2009.

BOURDIEU, Pierre. A economia das trocas linguísticas: o que falar quer dizer. São Paulo: EdUSP, 1996.

DALCASTAGNÈ, Regina. Vozes nas sombras: representação e legitimidade na narrativa contemporânea. In: DALCASTAGNÈ, Regina (org.). Ver e imaginar o outro: alteridade, desigualdade, violência na literatura brasileira contemporânea. São Paulo: Horizonte, 2008. 
D'ANGELIS, Wilmar da Rocha. Como nasce e por onde se desenvolve uma tradição escrita em sociedade de tradição oral? Campinas: Curt Nimuendajú, 2007.

FINNEGAN, Ruth. O significado da literatura em culturas orais. In: QUEIROZ, Sônia. $A$ tradição oral. Belo Horizonte: UFMG, 2006.

FOUCAULT, Michel. A ordem do discurso. Trad. Laura Fraga de Almeida Sampaio.14. ed. São Paulo: Loyola, 2006.

JECUPÉ, Kaka Werá. Todas as vezes que dissemos adeus. São Paulo: TRIOM, 2002.

MATO, Daniel. Para além da academia: práticas intelectuais latino-americanas em cultura e poder. In: MARGATO, Izabel; GOMES, Renato Cordeiro (orgs.). O papel do intelectual hoje. Belo Horizonte: UFMG, 2004.

MENEZES, Ana Luisa Teixeira de.; BERGAMASCHI, Maria Aparecida. A escola na cosmologia guarani: encontro de ambiguidades? In: MENEZES, Ana Luisa Teixeira de., BERGAMASCHI. Educação ameríndia: a dança e a escola guarani. Santa Cruz do Sul: EDUNISC, 2009.

SÁ, Lúcia. Anti-colonialismo na pós-colônia: Kaka Werá Jecupé ou a literatura indígena da megalópolis. In: SANCHES, Manuela Ribeiro (org.). Portugal não é um país pequeno: contar o império na pós-colonialidade. Lisboa: Cotovia, 2006.

WALTY, Ivete Lara Camargos. Corpus rasurado: exclusão e resistência na narrativa urbana. Belo Horizonte: Autêntica, 2005. 